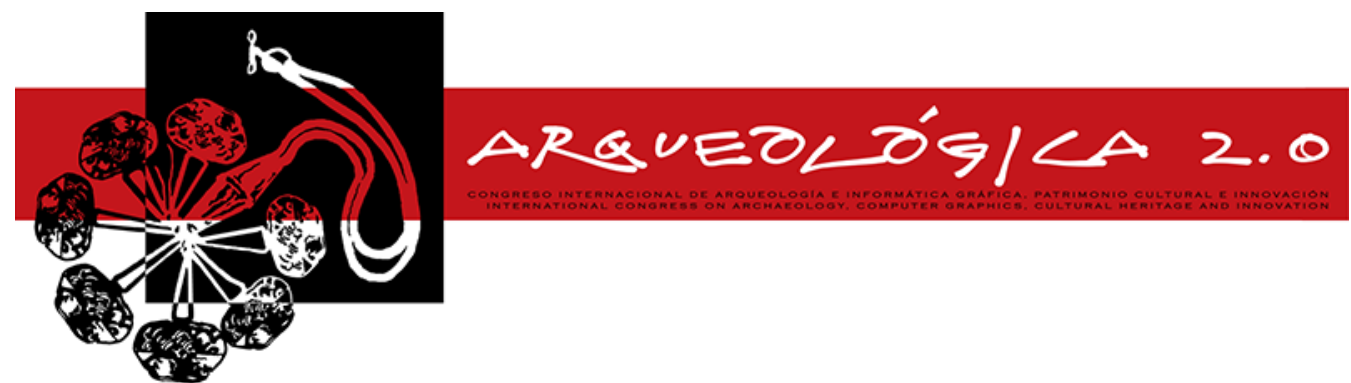

Proceedings of the $8^{\text {th }}$ International Congress

on Archaeology,

Computer Graphics,

Cultural Heritage and Innovation

'ARQUEOLÓGICA 2.0'

in Valencia (Spain),

Sept. 5-7, 2016

DOI: http://dx.doi.org/10.4995/arqueologica8.2016.3036

Received: $14 / 02 / 2016$

Accepted: 01/06/2016

\title{
LA VIRTUALIZACIÓN EN EL MUSEO ARQUEOLÓGICO DE BURRIANA (CASTELLÓN - ESPAÑA)
}

\author{
VIRTUALIZATION IN THE ARCHAEOLOGICAL MUSEUM OF BURRIANA(CASTELLÓN - SPAIN) \\ José Manuel Melchor ${ }^{\mathrm{a},{ }^{,},}$Jose Martínez ${ }^{\mathrm{b}}$, Carlos Bonafe ${ }^{\mathrm{b}}$, Alicia Cabrera ${ }^{\mathrm{b}}$ \\ ${ }^{a}$ Museo Arqueológico Municipal de Burriana, Plaza de la Merced s/n, 12530 Burriana, España. arqueologo@burriana.es \\ ${ }^{\mathrm{b}}$ Photocad-Fablabvlc, Camino de Vera, Edificio 8L 1, 46022 Valencia, España. fablabvalencia@gmail.com
}

\begin{abstract}
:
The Municipal Archaeological Museum of Burriana began the virtualization of parts and elements of cultural heritage and historic buildings in the early years of this century. Tangible results showed up from 2010. Regarding to archaeological artifacts two basic lines of action have been explored; on the one hand, literal documentation of pieces for later exhibition in augmented reality displays. Secondly, the research in the virtual recreation of missing elements or in the reconstruction of pieces. About the issue of cultural heritage we are currently in the documentation of buildings and archaeological excavations for augmented reality or didactic stage. We will also briefly discuss the prospects in the current virtualization works.
\end{abstract}

Key words: virtual archeology, museum, Burriana, cultural heritage, documentation, 3D reconstruction

\section{Resumen:}

La virtualización de piezas, elementos del patrimonio cultural y edificios de valor histórico empezó a desarrollarse en el Museo Arqueológico Municipal de Burriana desde los primeros años del siglo XXI, aunque los resultados tangibles empiezan a mostrarse a partir del año 2010. En la vertiente de los artefactos arqueológicos se han buscado dos líneas básicas de actuación; por un lado la documentación de literal de piezas para su posterior exhibición en montajes de realidad aumentada, y por otro la investigación en la recreación virtual de elementos faltantes o reconstrucción de piezas. En el aspecto del patrimonio inmueble por el momento solamente se ha procedido a la documentación de edificios y excavaciones arqueológicas para fines de realidad aumentada o de didáctica. También expondremos brevemente las perspectivas de futuro en los actuales trabajos de virtualización.

Palabras clave: arqueología virtual, museo, Burriana, patrimonio cultural, documentación, reconstrucción 3D

\section{Antecedentes de la cuestión}

El Museo Arqueológico Municipal de Burriana tiene sus antecedentes en las colecciones de principio del siglo $\mathrm{XX}$ que existían en el municipio, sin embargo, su origen más directo se debe a su refundación en el año 1967. Con la entrada de un nuevo equipo directivo en el año 2005 empieza un largo proceso de cambio museológico y museográfico. Desde el año 2010 se está llevado a cabo la introducción en el Museo Arqueológico Municipal de Burriana de nuevas tecnologías asociadas con la arqueología y el patrimonio cultural; estas discurren por dos líneas básicas: la divulgación expositiva y la investigación arqueológica.

Los primeros trabajos se centraron en la reconstrucción de elementos cerámicos de época musulmana (Pasíes et al. 2011), dentro de la línea de rehacer los faltantes en las piezas (incluida la decoración) sin tener que recurrir a una actuación física directa sobre el artefacto arqueológico (Fig. 1). Otro ejemplo fue la actuación sobre una moneda romana del yacimiento de Sant Gregori (Ferrer et al. 2013), que gracias a su virtualización y una animación básica, permitía al visitante del museo observar el anverso y el reverso de la moneda.

Al mismo tiempo se realizaron experimentos a nivel de reconstrucción en 3D de los restos arquitectónicos de la villa romana de Sant Gregori (Melchor 2013), concretamente se actuó sobre la balsa del peristilo (uno de los elementos mejor conservados detectados en la excavación), la cual, mediante el análisis de los restos conservados, pudo ser reconstruida virtualmente sobre

*Corresponding Author: Jose Manuel Melchor, arqueologo@burriana.es 
la actual hipótesis de trabajo, obtenida gracias a los fragmentos recuperados en la intervención, tanto a nivel del cromatismo de la pintura que la recubría, como de restitución del nivel de agua de su interior (Fig. 2).

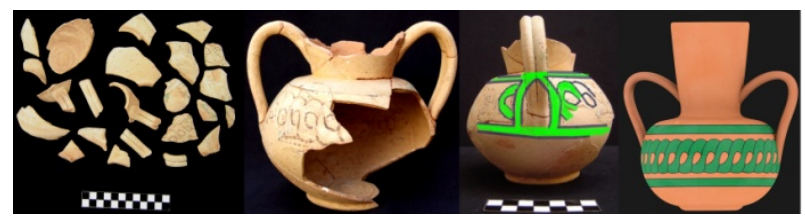

Figura 1: Restauración, documentación y reconstrucción digital de una jarrita musulmana.

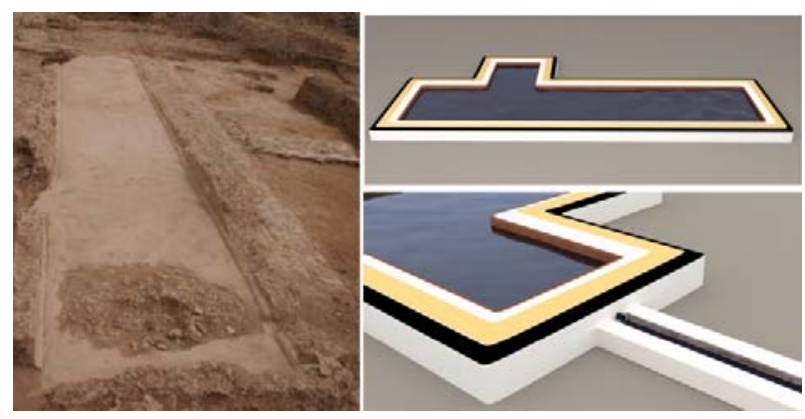

Figura 2: Excavación de la balsa del peristilo de Sant Gregori y su reconstrucción virtual.

En la actualidad ninguno de estos ejemplos se encuentra expuesto en las vitrinas del Museo Arqueológico de Burriana, ya que sus salas cuentan con ejemplos más avanzados, tanto tecnológicamente como a nivel de investigación arqueológica. Sin embargo, los casos citados si han servido como importantes herramientas de análisis en los campos de la arqueología y la conservación-restauración de piezas.

\section{La documentación virtual de restos arquitectónicos}

Una de las vertientes de las nuevas tecnologías introducidas en las estancias del Museo Arqueológico de Burriana es la reproducción de edificios históricos del municipio, de tal forma que en las pantallas de determinadas salas se pueden observar reproducciones de los mismos, obtenidas mediante fotogrametría y técnicas de modelado 3D paramétrico.

En los propios monumentos que no se encuentran permanentemente abiertos al público, se ha insertado un código QR en sus fachadas, que permite acceder a los videos expuestos en el Museo Arqueológico de Burriana mediante páginas web municipales.

En las representaciones, actualmente visualizadas mediante videos, se ha buscado dar a conocer la globalidad de los edificios, no solamente mediante vistas de todos sus paramentos y salas, sino que también por secciones que permitan ver su disposición interior (Fig. 3). También se han añadido textos explicativos relativos a los inmuebles, tanto en lo concerniente a sus datos históricos, como a su funcionalidad.

Lo citado más arriba es lo que actualmente se encuentra accesible al público o en la red, pero existen modelos interactivos, que permiten al visitante organizar su propio recorrido.
Hasta el momento se han realizado trabajos sobre cuatro edificios emblemáticos de Burriana: la torre de Carabona del siglo XVI (Melchor 2013), la torre del Mar de época Moderna (Melchor 2015), los depósitos de agua potable decimonónicos y la iglesia medieval del Salvador (Melchor 2011).

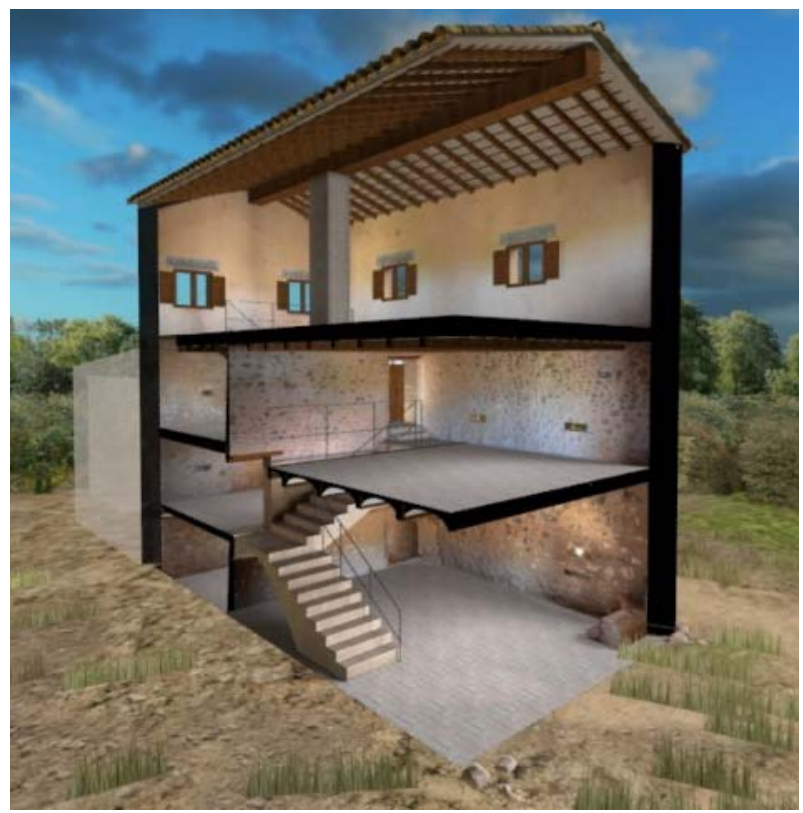

Figura 3: Sección virtual de la Torre de Carabona.

Lo citado más arriba es lo que actualmente se encuentra accesible al público o en la red, pero existen modelos interactivos, que permiten al visitante organizar su propio recorrido.

Hasta el momento se han realizado trabajos sobre cuatro edificios emblemáticos de Burriana: la torre de Carabona del siglo XVI (Melchor 2013), la torre del Mar de época Moderna (Melchor 2015), los depósitos de agua potable decimonónicos y la iglesia medieval del Salvador (Melchor 2011).

Queremos hacer hincapié en el último de estos ejemplos, ya que aquí también se han documentado los restos de la excavación arqueológica de la nueva casa abadía del Salvador, donde aparecieron relevantes estructuras medievales (Melchor 2011). Tal era la importancia de las mismas que se modificó el proyecto original de cimentación para realizar una losa que salvaguardara los restos. Lamentablemente no hubo acuerdo con la propiedad ni recursos económicos para poner en valor esos restos que actualmente permanecen ocultos, pero gracias a su documentación mediante fotogrametría, ahora existe la posibilidad de visualizarlos de una forma mucho más completa y dinámica (Fig. 4) que mediante una serie de fotos fijas.

\section{La documentación virtual de piezas}

Para el montaje de una vitrina del Museo Arqueológico de Burriana que emplea la realidad aumentada (esta vitrina se creó en el año 2014) se han empleado dos técnicas (fotogrametría y laser escáner) sobre piezas del museo. El objetivo del uso de realidad aumentada es permitir al visitante visualizar varios ángulos de una pieza que no son observables desde la vitrina donde se 
encuentra, como es el caso de la cratera griega de Orleyl (Melchor et al. 2010), pieza en la que se permite observar virtualmente no solamente toda su decoración exterior, sino que además se accede a una vista de su interior.

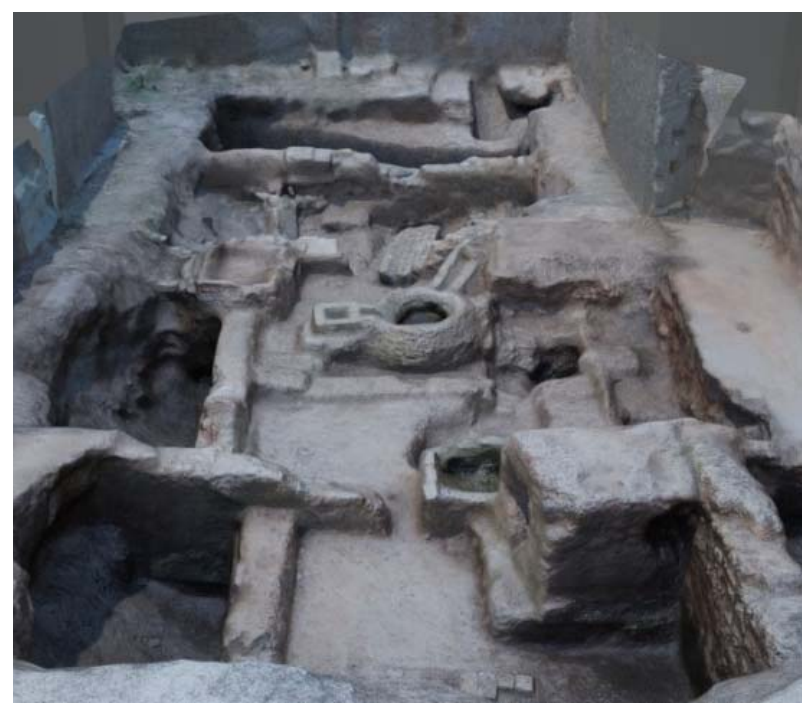

Figura 4: Reproducción virtual de la excavación de la casa abadía del Salvador.

Lo mismo sucede con el aplique cerámico helenístico con cabeza de Deméter del yacimiento de Torre d'Onda (Burriana) y el cráneo calcolítico del Argilagar de Morella (Mesado y Andrés 1999). En otros casos como la estatuilla de bronce romana del Hermes de Xilxes (Mesado 1971) y el candil medieval judío de Burriana (Utrilla 1966), también se exponen hipótesis interpretativas plasmadas en el resultado final de la realidad aumentada y que explicaremos con detalle en el siguiente apartado.

\section{La virtualización y la investigación arqueológica}

Las herramientas informáticas nos han permitido avanzar en la investigación de determinadas piezas, sin tener que actuar físicamente sobre ellas. Esto, en nuestra opinión, significa un gran avance desde el punto de vista de la conservación de las mismas, pues evita que la presentación al público del aspecto original de estas piezas, implique en tratamientos agresivos hacia ellas, como por ejemplo: reintegraciones, limpiezas o prótesis (sean miméticas o no), en la búsqueda de alcanzar una aspecto visual actual más cercano al antiguo.

También desde el punto de vista de los trabajos de documentación arqueológica significa una importante herramienta de apoyo, pues prácticamente elimina el uso de elementos como los calcos, dibujos, etc.; lo que sin duda agiliza y abarata estos trabajos (Fig. 5).

\subsection{Candil judío}

Se trata de un lámpara de aceite de seis picos con cubierta vítrea y decorada en azul cobalto con motivos geométricos y vegetales; tiene una cronología de alrededor del siglo XIV y fue recuperada en la excavación del año 1965 que se llevó a cabo en la iglesia de la Sangre, situada en la antigua judería de Burriana (Utrilla 1966), de la que lamentablemente se conserva muy poca información.

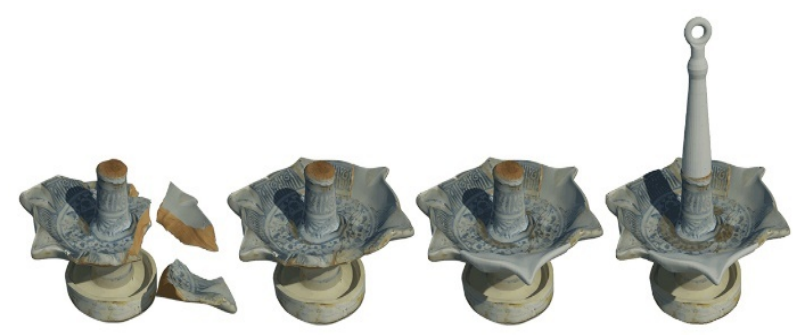

Figura 5: Proceso de análisis del candil judío.

Hasta hoy en día no se realizó ninguna intervención sobre la pieza, excepto la reintegración en escayola de parte de sus picos que se hizo al poco tiempo de su descubrimiento.

Durante el proceso actual de estudio de la pieza, localizamos un paralelo formalmente exacto de la misma en el museo del Tinell de Barcelona, sobre esta base se realizó la restitución virtual de la partes faltantes; en ellas se optó por no incluir decoración y mantener un color blanco que transmite un aspecto neutro y que sirve para diferenciar claramente las partes que son fruto de la interpretación arqueológica y las que son reales.

Pasaremos a describir brevemente el proceso seguido en cada uno de los elementos.

Para el proceso de documentación se realizó una toma de datos mediante escaneado fotogramétrico, con el cual se generó una nube de puntos de gran densidad que sirvió de base para el posterior tratamiento y virtualización 3D

Una vez obtenido el resultado deseado, o sea una reproducción virtual en 3D de la pieza, se decidió acrecentar un recurso de realidad aumentada cara a su exposición en el museo, consistente en añadir mechas encendidas y aceite en la cazoleta (Fig. 6), siendo que aquellas podían ser apagadas virtualmente con un gesto de la mano.

\subsection{Estatua de Hermes}

Se trata de una estatua de bronce macizo de pequeño tamaño que representa al dios Hermes (Fig. 7), y que fue encontrada alrededor del año 1966 por unos obreros, durante los trabajos de desfonde que arrasaron parte de la villa romana del Alter, en el municipio de Xilxes (Castellón), siendo posteriormente adquirida por el Museo Arqueológico Municipal de Burriana (Mesado 1971).

Esta pieza se encontraría originariamente en uno de los pequeños oratorios de la villa, los llamados lararios, que son habituales en las viviendas romanas de la época y es, por su calidad estilística, uno de los mejores ejemplos de la Comunidad Valencia de escultura romana en bronce de época romana altoimperial.

Desde su hallazgo la pieza sufrió un proceso de limpieza, se le añadió un anacrónico bastoncillo dorado en su mano izquierda y finalmente se pegó a una base cuadrangular maciza de mármol. Posteriormente, y 
obedeciendo a criterios museográficos mas actuales, en el año 2007, se retiró el bastoncillo y la base de mármol.

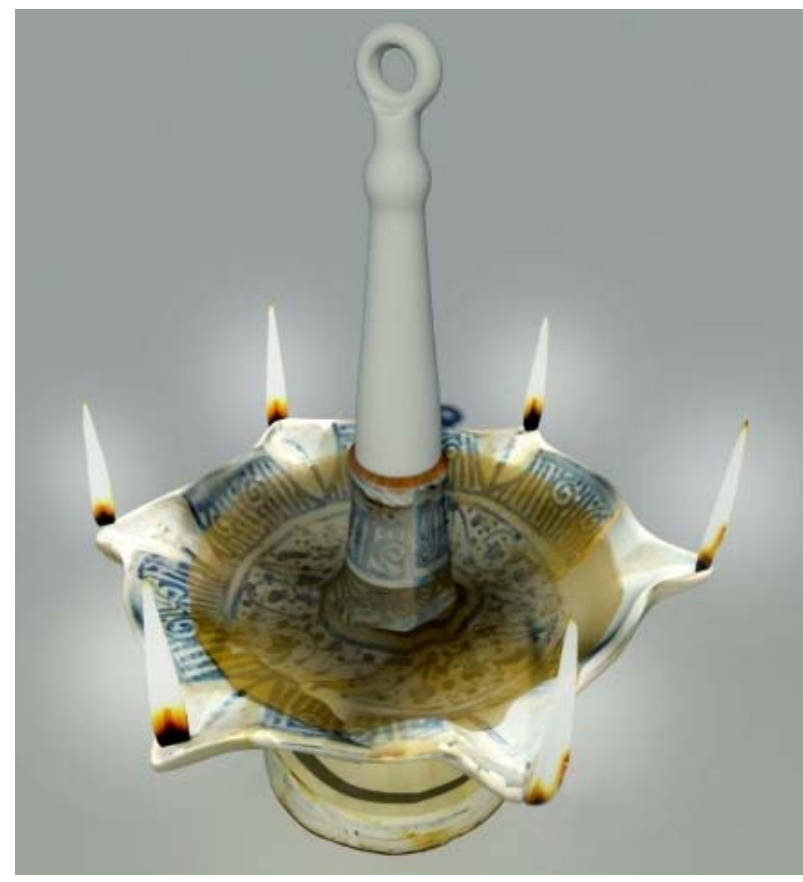

Figura 6: Reconstrucción virtual del candil judío.

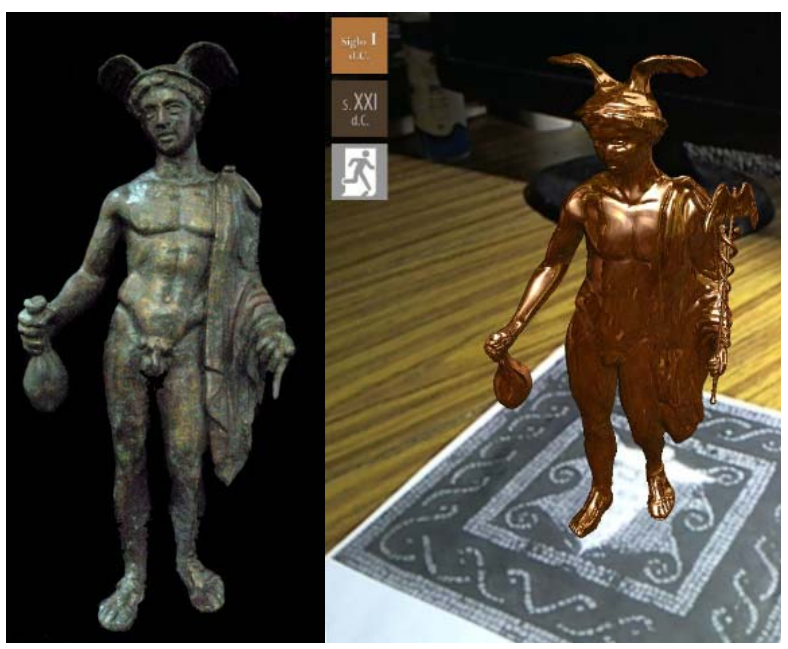

Figura 7: Hermes de Xilxes y su recreación virtual.

Para el proceso de documentación se realizó una toma de datos fotogramétrica y escaneado a pequeña escala de la pieza, consiguiendo precisiones inferiores al milímetro.

Por paralelos en otras estatuillas similares se estableció la hipótesis de que esta originariamente debería llevar un caduceo en su mano izquierda, ya que la posición de la misma es la propia para llevar este artefacto, que además es uno de los emblemas característicos de la divinidad.

Así pues, mediante un modelado virtual y reconstrucción 3D se añadió un caduceo a una escala aproximada a la que debería tener el original y posteriormente se reprodujo el tono del bronce recién fundido (sin patina y sin oxidación) para que el visitante al museo pueda tener una idea de su apariencia original (Fig. 8).
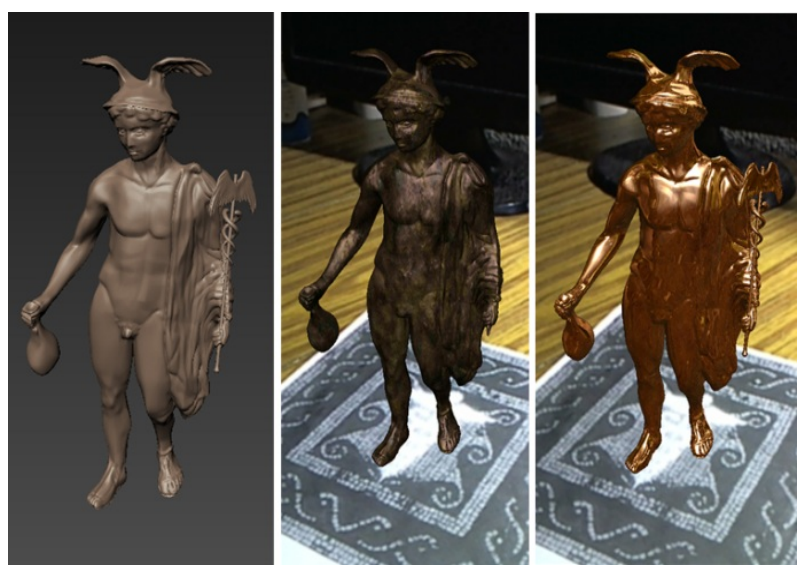

Figura 8: Proceso de trabajo del Hermes de Xilxes.

\subsection{Estatua de Livia}

Es una estatua de mármol blanco a tamaño natural de un mujer romana vestida con chitón, a la que le faltan todas las extremidades. Se trata de una pieza de una cierta calidad artística.

Fue traída al Museo Arqueológico Municipal de Burriana en los años 70 desde Talavera de la Reina (Mesado 1971), dentro de un contexto de otros materiales arqueológicos varios traídos de esta misma zona geográfica en aquel periodo.

La imagen aparentemente apareció en el derribo de un edificio de época moderna, donde había sido reutilizada como material constructivo, del cual aun conservaba restos de mortero y pintura en su superficie.

Desde que se incorporó al museo fue trasladada a varios sitios, hasta que finalmente en el año 2010 fue rescatada desde su ubicación en un soporte volado en la segunda planta de la Casa de Cultura de Burriana (donde había sido emplazada en el año 1991), y se le practicó la primera limpieza desde su descubrimiento. Posteriormente se le realizó una peana y desde entonces forma parte de la exposición permanente del museo en un lugar destacado de la misma.

Debido al tamaño de la pieza, el proceso de documentación se realizó exclusivamente mediante fotogrametría, consiguiendo excelentes resultados desde el modelo extraído en la propia toma, sin casi necesidad de postprocesado (Fig. 9).

La labor de documentación de paralelos fue compleja debido a la variedad de la estatuaria romana y se acotó a efigies de Livia, esposa del emperador Augusto, con las cuales coincidía cronológica y estilísticamente la pieza talaverana.

Finalmente la posición de lo que restaba de las cuatro extremidades nos llevó a inclinarnos por interpretar la estatua como similar a una imagen de Livia divinizada, en este caso portando una cornucopia en la mano izquierda y una patera en la derecha; en estos casos es frecuente que la imagen tenga la cabeza cubierta por un velo como parte del ritual. Se trata de un modelo bastante usual en este periodo del imperio romano

Con estos datos realizamos dos propuestas de restitución: una canónica, añadiendo virtualmente las extremidades faltantes y diferenciando las texturas del 
original y los añadidos, simulando que la pieza hubiera sido objeto de una reintegración real, y otra opción donde proponemos el aspecto original de la estatua (Fig. 10).
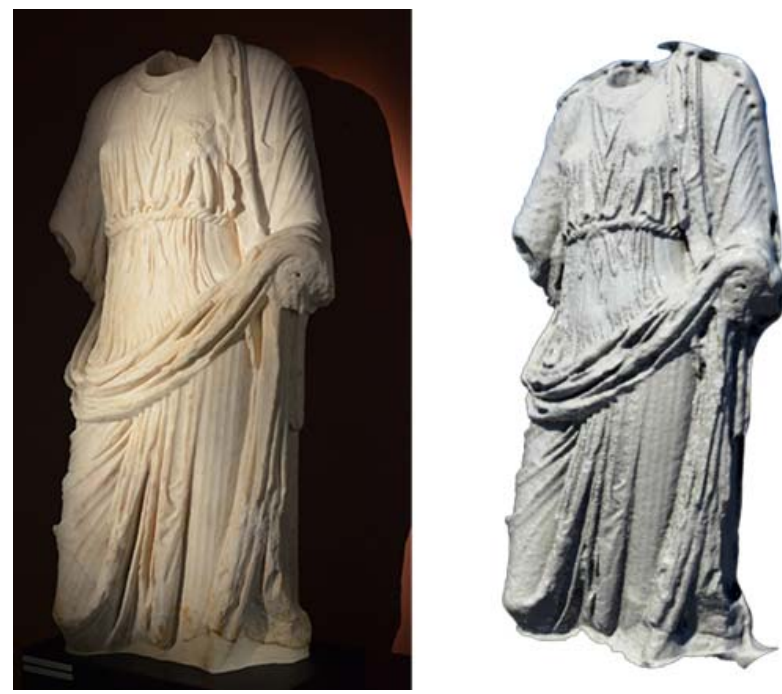

Figura 9: Estatua de Livia y su modelo virtual.
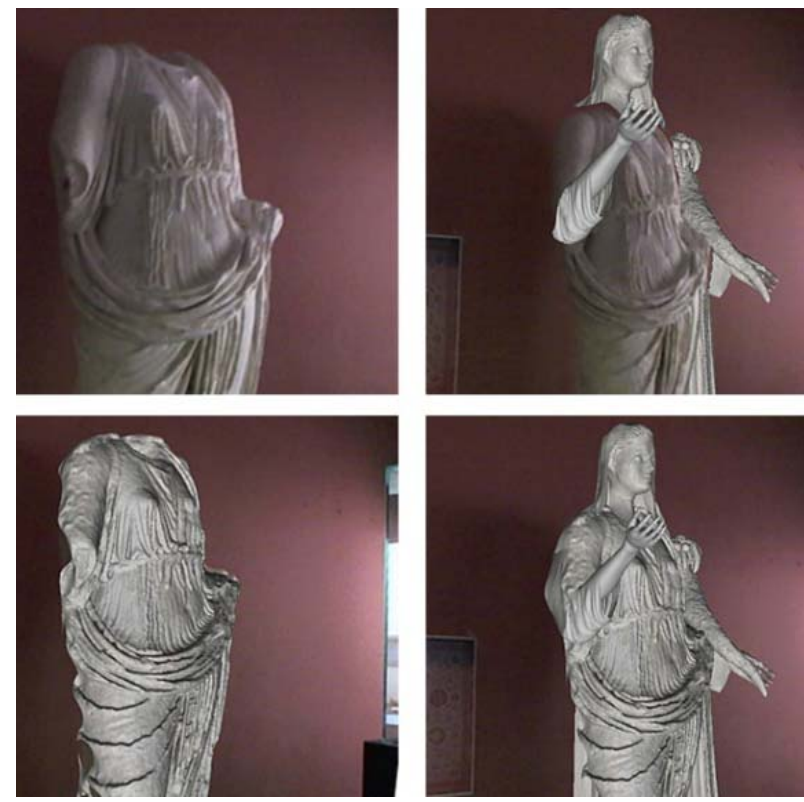

Figura 10: Estatua de Livia y su recreación virtual en el museo.

\subsection{Aplique cerámico de Deméter}

Se trata de un aplique cerámico helenístico del yacimiento ibero-romano de Torre d'Onda (Mesado et al. 1991) formado por una cabeza de arcilla maciza (probablemente la diosa Deméter), fabricada a molde, la cual se aplicó sobre la vasija y sobre ella se pegó una asa trenzada. Por su calidad y origen se trata de una pieza de excepcional interés en el contexto valenciano, donde además este tipo de piezas son muy escasas.

En este caso el procedimiento utilizado fue captación fotogramétrica a pequeña escala (Fig. 11). Con este procedimiento se buscó documentar más aspectos físicos de la pieza (arcilla, textura, superficies, etc.) debido a su excepcionalidad. Así también fue posible documentar no solo la existencia de restos de pintura, si no las propias características morfológicas de la pieza.

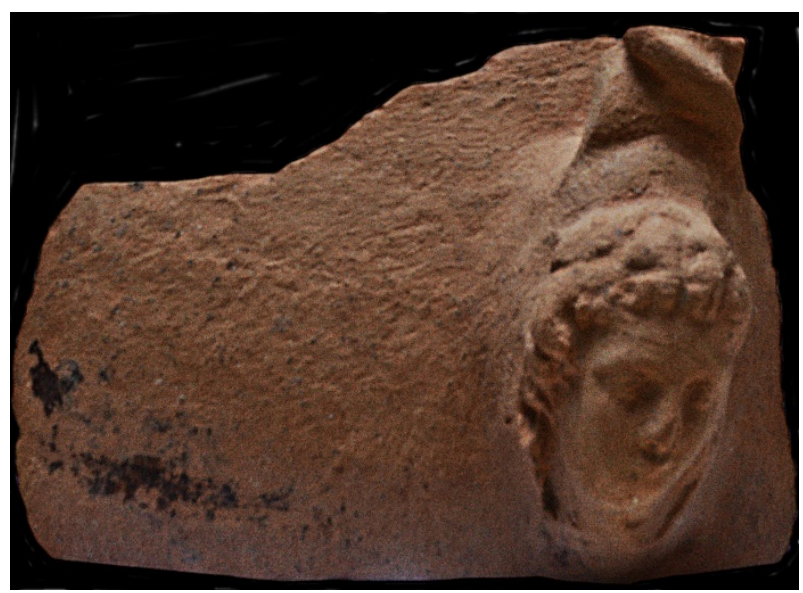

Figura 11: Escaneado de la cabeza cerámica de Deméter.

\section{Estado actual y propuestas de virtualización del museo}

Actualmente la disposición dentro del discurso museográfico de las piezas reales que han sido virtualizadas es bastante dispersa.

Las estatuas de Livia divinizada y Hermes, además del aplique de Deméter, ocupan un espacio diferenciado dedicado a las divinidades en la sala de la cultura romana del Museo Arqueológico Municipal de Burriana.

El candil judío se encuentra en la vitrina que tiene por temática a las tres culturas (musulmana, judía y cristiana) de la Burriana medieval. Junto a esta parece la pantalla donde se muestran los videos de dos de los edificios históricos virtualizados ya citados en este artículo (Torre de Carabona y Torre del Mar). La cratera griega de Orleyl está ubicada en una vitrina dedicada exclusivamente a la necrópolis ibérica donde apareció, en el espacio del museo dedicado a la arqueología de la muerte.

Los artefactos virtualizados se muestran justo en la entrada del museo, entre sus primeras vitrinas dedicadas a la metodología arqueológica y la restauración. Allí tenemos una pantalla dedicada a la realidad aumentada; donde aparecen la cratera de Orley, Hermes de Xilxes, cráneo del Argilagar de Morella y candil judío de Burriana (Fig. 12).

Gracias a la línea de investigación arqueológica y museológica que se está siguiendo desde el Museo Arqueológico Municipal de Burriana, sumada al constante proceso de aplicación de nuevas tecnologías, está previsto implementar en el museo otro tipo de interacciones, además de ampliar las ya existentes.

En estos momentos se está trabajando en instalaciones de videomapping, realidad aumentada con base en tecnología móvil, y visitas virtuales $360^{\circ}$ relacionadas con piezas y salas del museo. 


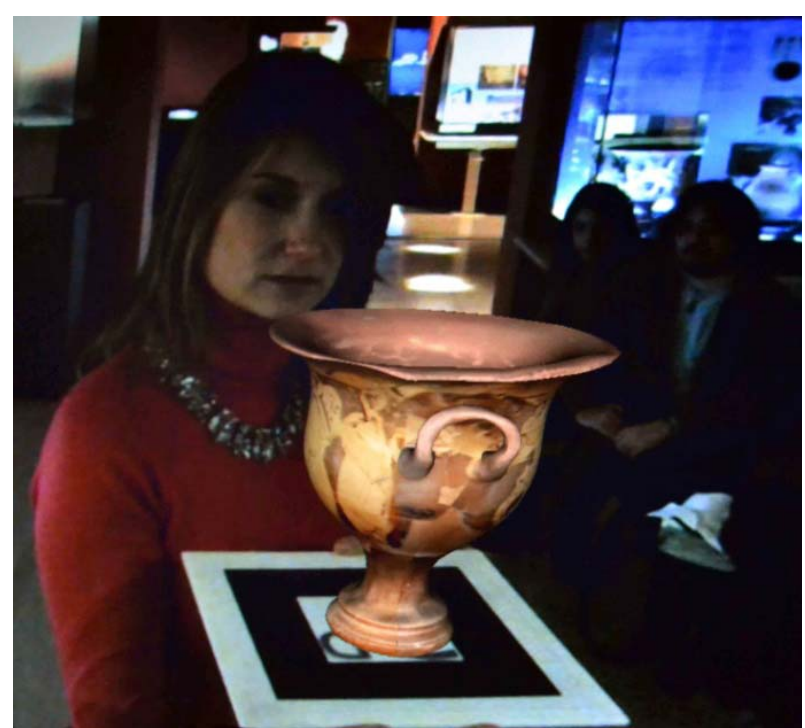

Figura 12: Vitrina de realidad aumentada del Museo de Burriana con una vista de la cratera de Orleyl.

\section{Conclusión}

La aplicación de estas nuevas tecnologías permite crear un espacio virtual dentro del museo que admite exhibir inmuebles o piezas que seria imposible introducir en las salas por motivos obvios.

Pero no solo eso, también permite enseñar a los visitantes propuestas de reintegración o reconstrucción de piezas que no solo mantienen inalterado el artefacto, si no que permiten su modificación y modernización constante.

\section{Referencias}

FERRER, J.J., MELCHOR, J.M. y BENEDITO, J., 2013. Sant Gregori. Un complejo arquitectónico de época romana en la costa de Burriana (España). Millars, XXXVI, pp. 129-233. DOI:dx.doi.org/10.6035/Millars.

MELCHOR, J.M., 2011. La arqueología como fuente de estudio para la Burriana medieval. En: J.M. MELCHOR, J. BENEDITO y T. PASIES, eds, La arqueología de la Buriyyana islámica a la Borriana cristiana. Conselleria de Governació de la Generalitat Valenciana, pp. 11-48.

MELCHOR, J.M., 2013. Diez años del Servicio Arqueológico Municipal de Burriana, Ayuntamiento de Burriana. 160 páginas.

MELCHOR, J.M., 2015. Datos históricos sobre la Torre del Mar (Burriana - Castellón), en Defensive Architecture of the Mediterranean. XV to XVIII centuries, Vol I, P. Rodríguez-Navarro (ed.), Universidad Politécnica de Valencia, pp. 113-116. DOI: 10.4995/FORTMED2015.2015.1678.

MELCHOR, J.M., FERRER, J.J. y BENEDITO, J., 2010. El enterramiento ibérico de la "Cratera de la Grifomaquia" de Orleyl, Millars, XXXIII, pp. 39-54. DOI:dx.doi.org/10.6035/Millars

MESADO, N., 1971. Estatua femenina y mercurio del Museo de Burriana (Castellón). AEspArq. 123-24. Pp. $169-71$.

MESADO, N. y ANDRÉS, J., 1999. La necrópolis megalítica del Argilagar del Mas de García (Morella, Castellón). Archivo de Prehistoria Levantina, XXIII. Pp. 85-156

MESADO, N., GIL, J.L. y RUFINO, A., 1991. El Museo Histórico Municipal de Burriana, Ayuntamiento de Burriana. 107 paginas.

PASIES, T., PEIRÓ, M.A. y TEJERINA, D., 2011. La conservación-restauración en arqueología. Trabajos en el laboratorio del Museo Arqueológico de Burriana. En: J.M. MELCHOR, J. BENEDITO y T. PASIES, eds, La arqueología de la Buriyyana islámica a la Borriana cristiana. Conselleria de Governació de la Generalitat Valenciana, pp. 137-152.

UTRILLA, T., 1966. Sobre los orígenes de Burriana. Su sinagoga e iglesia de la Sangre, BurisAna. 99. pp. 10-13. 